\title{
Evidence from 617 laboratories in 47 countries for SLMTA-driven improvement in quality management systems
}

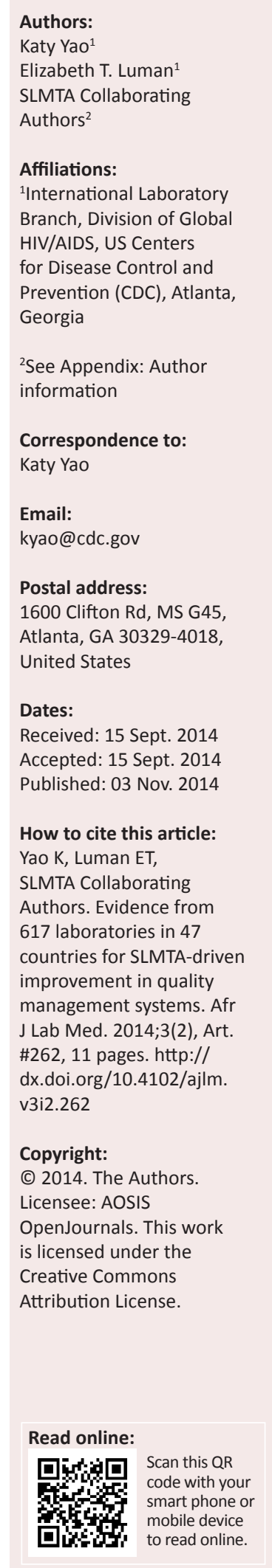

Background: The Strengthening Laboratory Management Toward Accreditation (SLMTA) programme is a large-scale effort to improve the quality of laboratories in resource-limited countries.

Objectives: This study sought to evaluate the first four years (2010-2013) of SLMTA implementation.

Methods: Country-level data were submitted by SLMTA programme leads and compiled globally. Performance was measured before (baseline) and after (exit) SLMTA implementation using an audit checklist which results in a percentage score and a rating of zero to five stars. Some laboratories continued to monitor performance in post-exit surveillance audits. We evaluated score improvements using two-tailed $t$-tests for equal variances and estimated the number of tests performed by SLMTA laboratories based on star level.

Results: SLMTA was implemented in 617 laboratories in 47 countries in Africa, the Caribbean, Latin America and Southeast Asia. At the baseline audit, the laboratories scored an average of $39 \%$ on the checklist and $84 \%$ of them were rated below one star. As of December 2013, 302 laboratories had completed the SLMTA programme; mean checklist scores increased from $39 \%$ at baseline to $64 \%$ at exit $(p<0.001)$ over an average 16 -month programme duration. Ninety-two laboratories conducted a surveillance audit at a median of 11 months after their exit audit; $62 \%$ further increased their performance. Six SLMTA laboratories have achieved accreditation status. In total, the 617 SLMTA laboratories conduct an estimated 111 million tests annually. Only $16 \%$ of these tests were conducted by laboratories with at least one star at baseline, which increased to $68 \%$ of tests after SLMTA training. Thus, approximately 23 million tests are conducted annually by laboratories previously at zero stars that now have one to five stars; this number is projected to increase to 58 million when currently-enrolled laboratories complete the programme.

Conclusion: SLMTA has transformed the laboratory landscape in resource-limited countries worldwide and has the potential to make a substantial and sustainable impact on the quality of laboratory testing and patient care.

\section{Introduction}

Substantial resources have been invested in management training and development to help scale up and improve the quality of health services in order to reach the United Nation's Millennium Development Goals. ${ }^{1}$ However, evidence is scarce in terms of the impact that has actually been achieved. An international meeting convened by the World Health Organization (WHO) in 2005 on strengthening leadership and management in low-income countries concluded that programme evaluation often focuses on the number of trainees and pre-/post-knowledge-based tests; evaluation of programme impact on managers' daily work and job outcomes is more the exception than the norm. ${ }^{2}$

Strengthening Laboratory Management Toward Accreditation (SLMTA) is a large-scale effort aimed at improving the quality of laboratory services and patient care in resource-limited settings by developing competent laboratory managers. SLMTA provides an innovative training curriculum on implementing practical Quality Management Systems (QMS) using existing resources with built-in accountability and evaluation that focuses on result-oriented outcome measures. ${ }^{3}$ Launched in 2009 in Kigali, Rwanda, this programme seeks to engage laboratories in continuous quality improvement and to accelerate their preparations toward accreditation to international standards. ${ }^{4,5}$

In this article, we present evidence from the first four years of SLMTA programme implementation (2010-2013). We report data on changes in levels of laboratory compliance with 
International Organization for Standardization (ISO) 15189 requirements using the WHO Regional Office for Africa's (WHO AFRO) accreditation preparedness checklist. The findings from this unprecedented study shed light on the widespread success of an innovative programme that has empowered laboratory teams throughout the developing world to strive for continuous quality improvement and work toward accreditation, despite limited resources.

\section{Research methods and design SLMTA implementation and evaluation}

The methodology of the SLMTA programme has been described previously. ${ }^{3,5}$ Briefly, SLMTA is a competencybased programme that uses a series of short courses and work-based learning projects to effect rapid and measurable laboratory improvement for better patient care through enhanced management skills and implementation of practical quality management systems. The SLMTA training programme is based on a series of three workshops. After each workshop, participants implement improvement projects supported by regular supervisory visits or on-site mentoring. Laboratories are evaluated using WHO AFRO's Stepwise Laboratory Quality Improvement Process Towards Accreditation (SLIPTA) checklist, ${ }^{6}$ which includes 111 items divided into 12 sections that represent the 12 Quality System Essentials (QSEs). ${ }^{7}$ In order to assess progress made by the laboratories, audits are conducted using the SLIPTA checklist at the beginning (baseline) and at the end (exit) of the SLMTA programme. Many countries also conduct intermediate audits to help guide programme implementation, as well as surveillance audits after exiting the programme so as to monitor continued improvement and assess sustainability. After an audit, laboratories receive a score which determines their star rating - from zero to five, with $<55 \%$ corresponding to zero stars, $55 \%-64 \%$ one star, $65 \%-74 \%$ two stars, $75 \%-$ $84 \%$ three stars, $85 \%-94 \%$ four stars and $\geq 95 \%$ five stars.
When a laboratory achieves a five-star rating, it may be encouraged to seek accreditation.

\section{Data analysis}

Programme data up to December 2013 were collected from all countries implementing SLMTA. Variables included year of implementation, number and types of laboratories in each cohort (i.e., enrolment in the same training round), number of people trained, audit scores and approximate number of tests conducted by each laboratory. Data were collated and analysed in Microsoft ${ }^{\circledR}$ Excel 2013. Descriptive statistics (percentages, medians, ranges) were calculated. Statistical significance of improvements were assessed using 2-tailed $t$-tests for equal variances ( $f$-tests showed equal variances at $p>0.1$ ); comparison of improvements across laboratory types was assessed using one-way analysis of variance (ANOVA).

Given the wide variations in the time between the baseline audit and the first SLMTA workshop, programme length was defined as the time from the first SLMTA workshop to the exit audit. In some countries, results for large national reference laboratories were reported by department rather than for the laboratory as a whole. For consistency, we aggregated the department scores into a single score per laboratory, using median values across laboratory departments. We estimated the number of laboratory tests conducted in SLMTA laboratories based on country reports for 2012; missing data were imputed using averages by laboratory type.

\section{Results}

\section{Programme spread}

Since its introduction in 2009, SLMTA has been implemented in 47 countries worldwide, including 23 countries in Africa, 12 in the Caribbean Region, 10 in Central and South America, and two in Southeast Asia (Figure 1, Table 1).

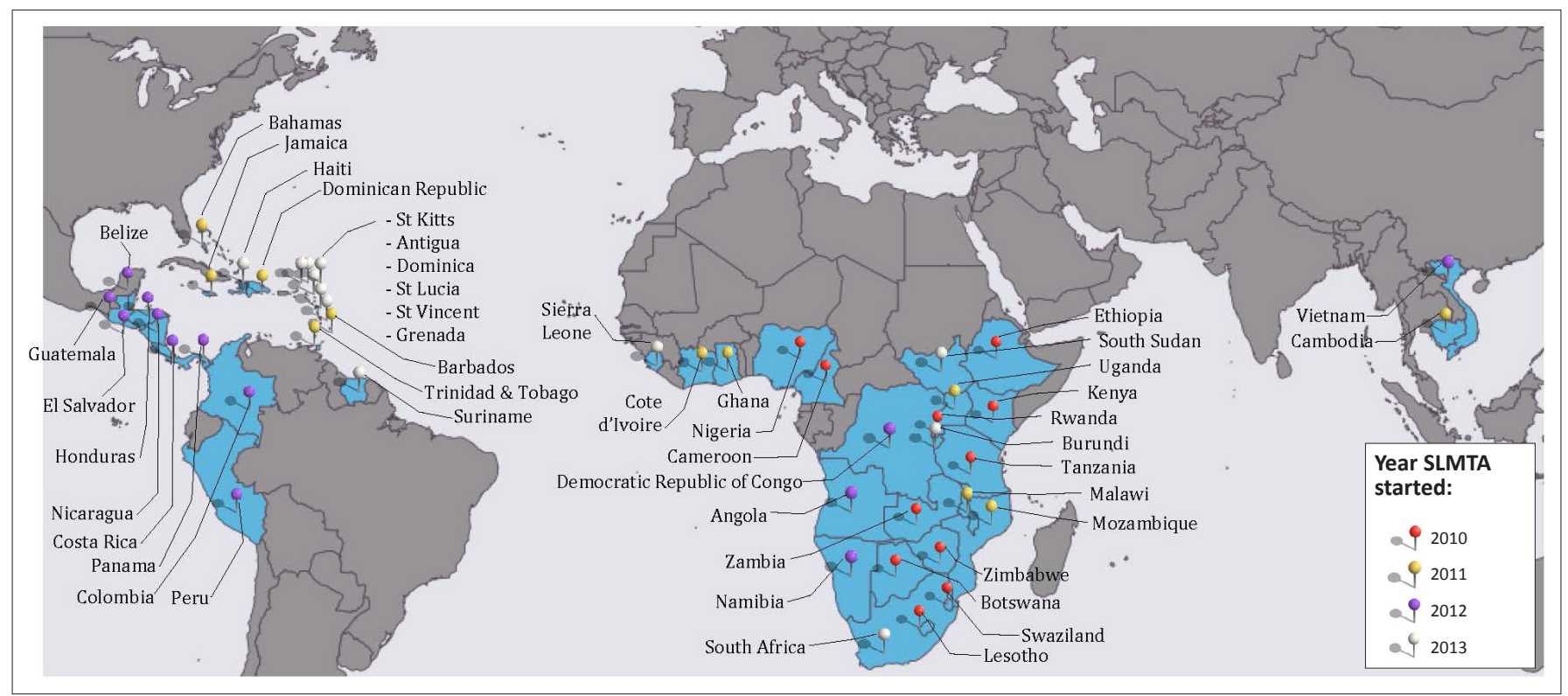

SLMTA, Strengthening Laboratory Management Toward Accreditation.

FIGURE 1: Global reach of SLMTA by year of implementation, 2010-2013 ( $n=47$ countries). 


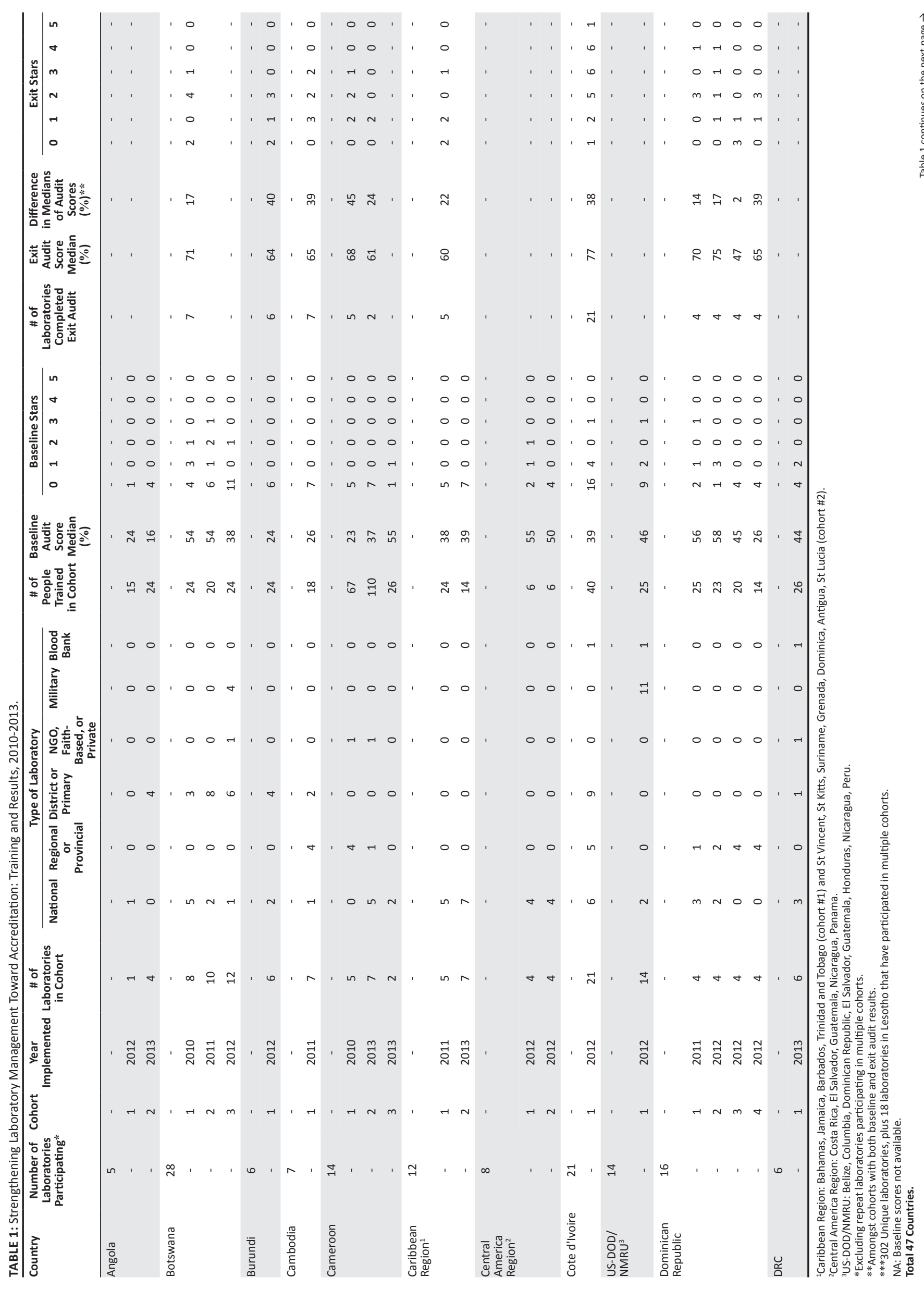




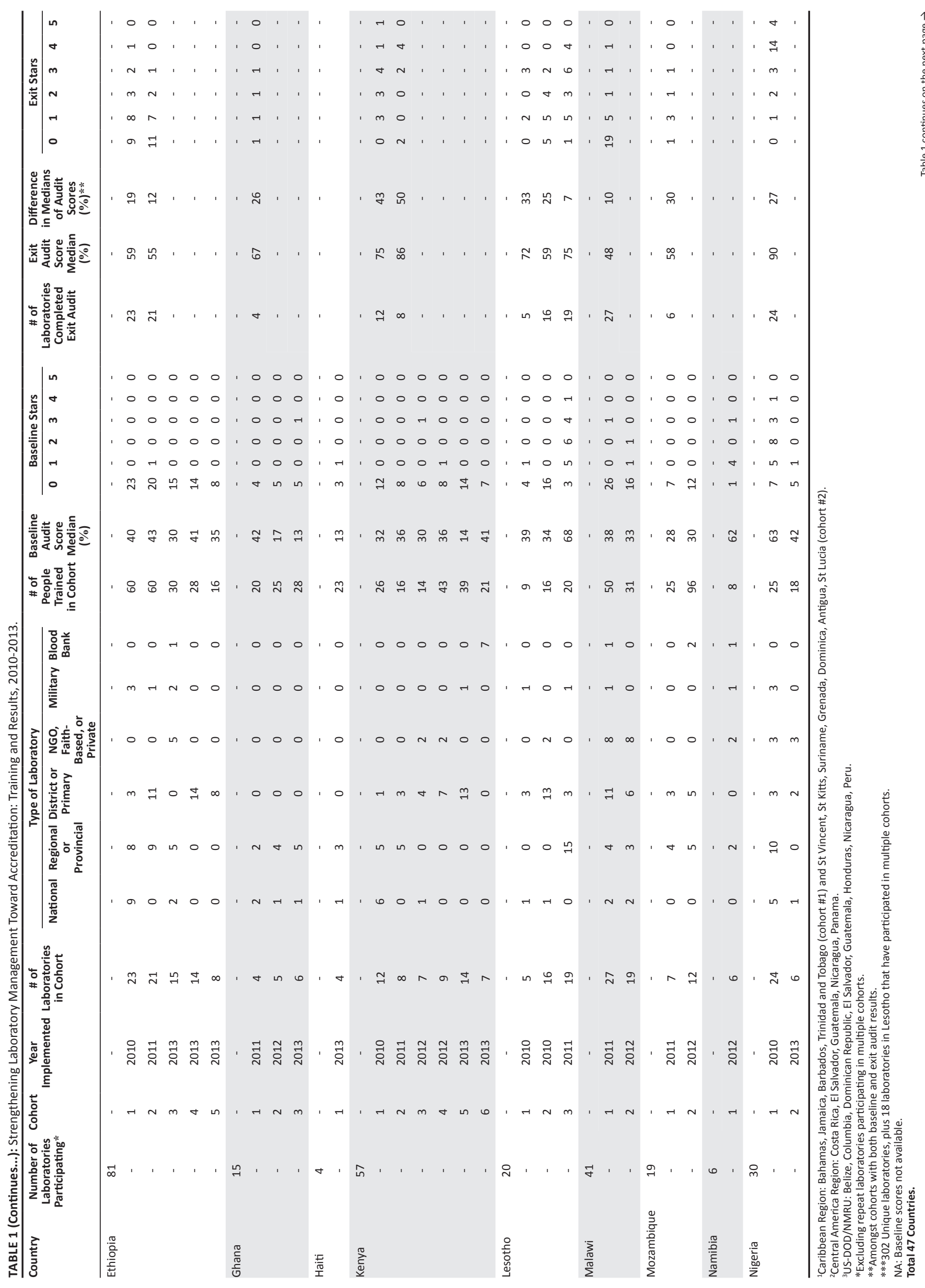




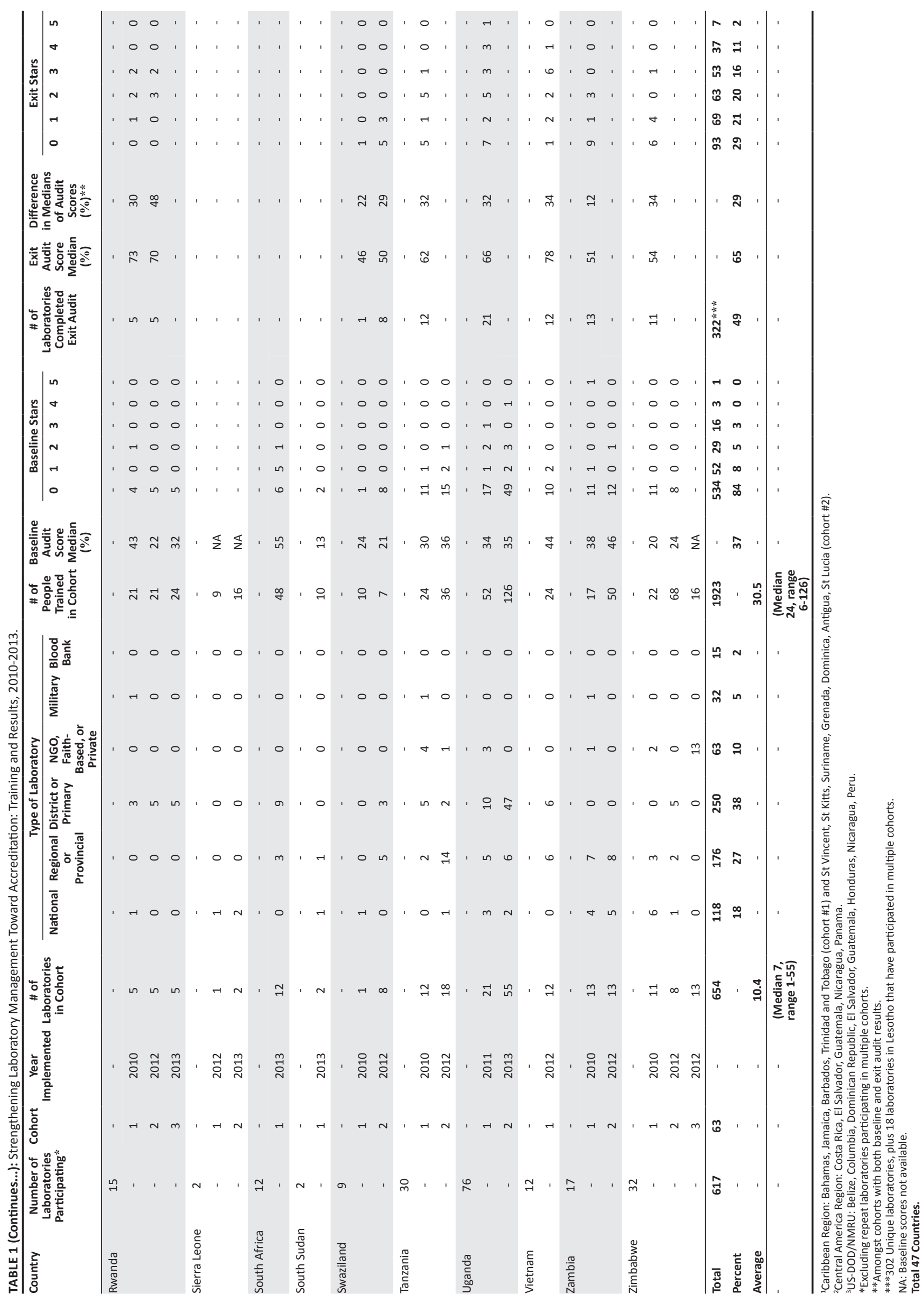


As of December 2013, 65 SLMTA cohorts had been initiated, with one to 55 laboratories per cohort. Thirty were first cohorts within countries, including three regional cohorts which encompassed multiple countries, whilst the remaining 35 were subsequent cohorts in 23 countries as they expanded the programme (Table 1).

A total of 1923 people from 617 laboratories were trained. Thirty-seven of these laboratories $(6 \%)$ were re-enrolled in a subsequent SLMTA cohort. Eighteen per cent of the 617 laboratories were at the national level, $27 \%$ at regional or provincial levels, $38 \%$ at district or primary levels, $10 \%$ belonged to non-governmental, faith-based or private organisations, $5 \%$ were military laboratories and $2 \%$ were blood banks. Nearly all (98\%) of these laboratories provide HIV-related services, such as HIV diagnosis, treatment monitoring, opportunistic infection or tuberculosis testing, and blood bank testing. Of these laboratories, 302 (49\%) completed the SLMTA programme and conducted an exit audit, whilst the remaining 315 (51\%) were still going through the programme at the time of this analysis.

\section{Audit results}

At the baseline audit, the mean score for all 617 SLMTAenrolled laboratories was 39\% (median 37\%) and 84\% received zero stars (i.e., score $<55 \%$ ) on the SLIPTA five-star scale (Table 1). For the 302 laboratories that had completed the programme and conducted an exit audit, mean scores increased from $39 \%$ at baseline to $64 \%$ at exit $(p<0.001)$. Whilst $85 \%$ had received zero stars at baseline, only $30 \%$ remained at zero stars at exit (Figure 2).

The average improvement from baseline to exit audit was 25 percentage points over a mean programme duration of 16 months. Sixty-eight per cent of laboratories improved by at least one star, including $22 \%$ that increased by three or more stars. Although $32 \%$ of the laboratories did not increase their stars, $23 \%$ of these more than doubled their scores from baseline to exit. Improvements tended to be higher for laboratories with lower baseline scores. Those with a starting score below $25 \%$ had an average increase of 37 percentage points, whilst those with a starting score of $65 \%$ or higher had an average increase of nine percentage points $(r=-0.49$, $p<0.001$ ) (Table 2).

Baseline and exit scores and improvements were similar between the different types of laboratories $(p>0.05)$ (Figure 3). Amongst laboratories that had completed the SLMTA programme, the 132 laboratories implementing SLMTA in the first year (2010) had the same mean improvement as the 170 laboratories implementing SLMTA in 2011 to 2013 (24 percentage points).

\section{Sustainability}

Ninety-two laboratories had conducted post-SLMTA surveillance audits, at a median of 11 months post-exit audit (range five to 28 months). Of these laboratories, 62\% further increased their score, including 34\% whose score increased by $>10$ percentage points post-exit audit (Figure 4). Of the national-level laboratories that conducted post-SLMTA audits $(n=19), 79 \%$ improved their scores, whilst only $56 \%$ of district-level laboratories $(n=27)$ further increased their

TABLE 2: Improvement by baseline level based on the Stepwise Laboratory Quality Improvement Process Towards Accreditation checklist.

\begin{tabular}{lcccc}
\hline Baseline level & $\boldsymbol{n}$ & $\begin{array}{c}\text { Mean baseline } \\
\text { audit score } \\
(\mathbf{\%})\end{array}$ & $\begin{array}{c}\text { Mean exit } \\
\text { audit score } \\
\mathbf{( \% )}\end{array}$ & $\begin{array}{c}\text { Mean change } \\
\text { (percentage } \\
\text { points) }\end{array}$ \\
\hline $0 \%-24 \%$ & 59 & 19 & 56 & 37 \\
$25 \%-34 \%$ & 66 & 30 & 56 & 26 \\
$35 \%-44 \%$ & 73 & 39 & 62 & 23 \\
$45 \%-54 \%$ & 59 & 48 & 68 & 20 \\
$55 \%-64 \%$ & 23 & 59 & 79 & 20 \\
$65 \%+$ & 22 & 75 & 84 & 9 \\
\hline Total & 302 & 39 & 64 & 25 \\
\hline
\end{tabular}

NGO, non-governmental organisation.

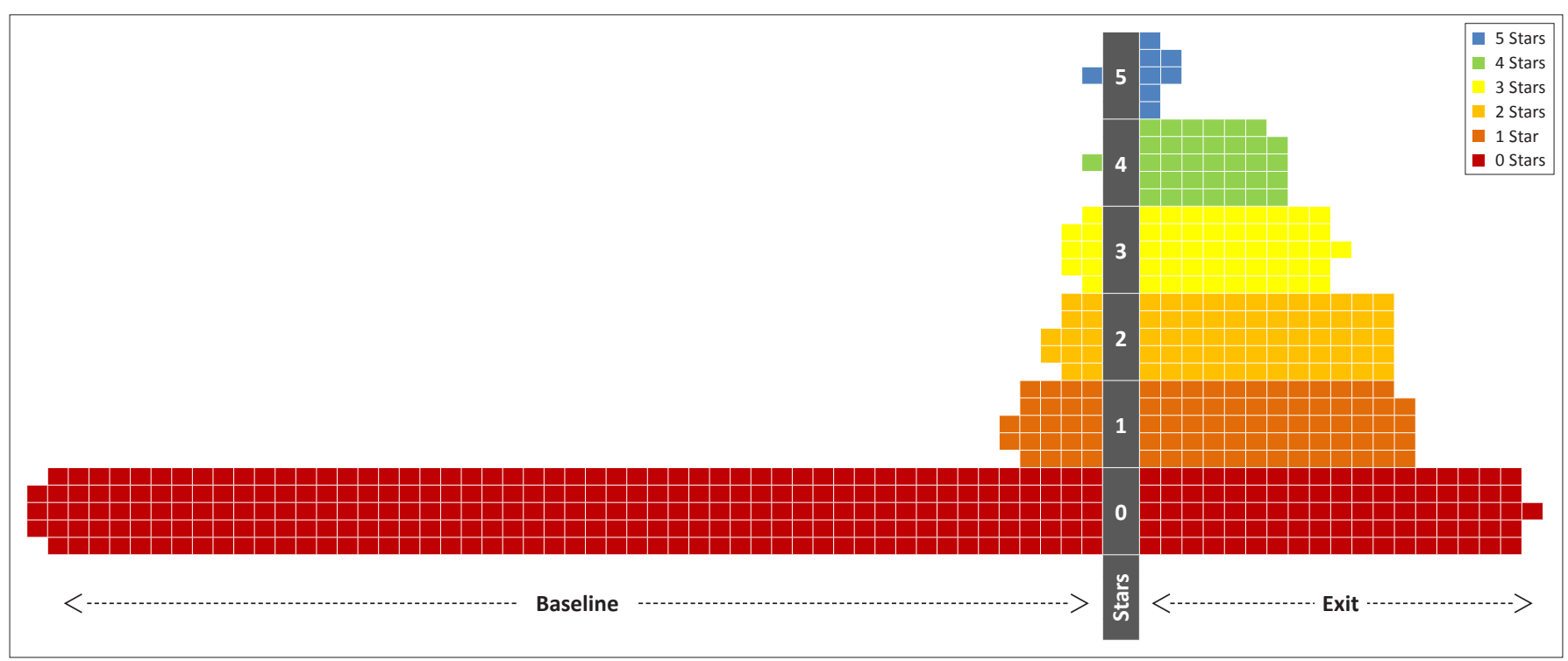

Note: Each square represents one laboratory.

FIGURE 2: Star levels at baseline and exit amongst the 302 laboratories completing the Strengthening Laboratory Management Toward Accreditation programme, 2010-2013. Results based on the Stepwise Laboratory Quality Improvement Process Towards Accreditation checklist baseline and exit audit scores. 
scores $(p=0.03)$. Overall, there was regression toward the mean, as laboratories that received lower scores at exit were more likely to improve their scores at the post-SLMTA audit $(r=-0.48, p<0.001)$.

As of September 2014, six SLMTA laboratories have been accredited to international standards (Table 3). These laboratories had baseline scores approximately equal to all SLMTA laboratories, with a median score of $38 \%$ (range $29 \%$ to $75 \%$ ) as compared to a median of $37 \%$ for all SLMTA laboratories; one of the laboratories started at three SLIPTA stars, whilst the other five laboratories began at zero stars. At the exit audit, the six laboratories had a median score of $90 \%$, with an increase of 52 percentage points, as compared to the international average of $64 \%$ and 25 percentage points. The median time from SLMTA initiation to accreditation was 31.5 months (range 17-54). In March 2013, the Kenya HIV National Reference Laboratory became the first SLMTA laboratory (and the first public medical laboratory in Kenya) to earn accreditation. ${ }^{8}$ The Hai Duong Preventive Medicine Center in Vietnam had the lowest baseline score of the six laboratories at $29 \%$, but achieved the greatest improvement

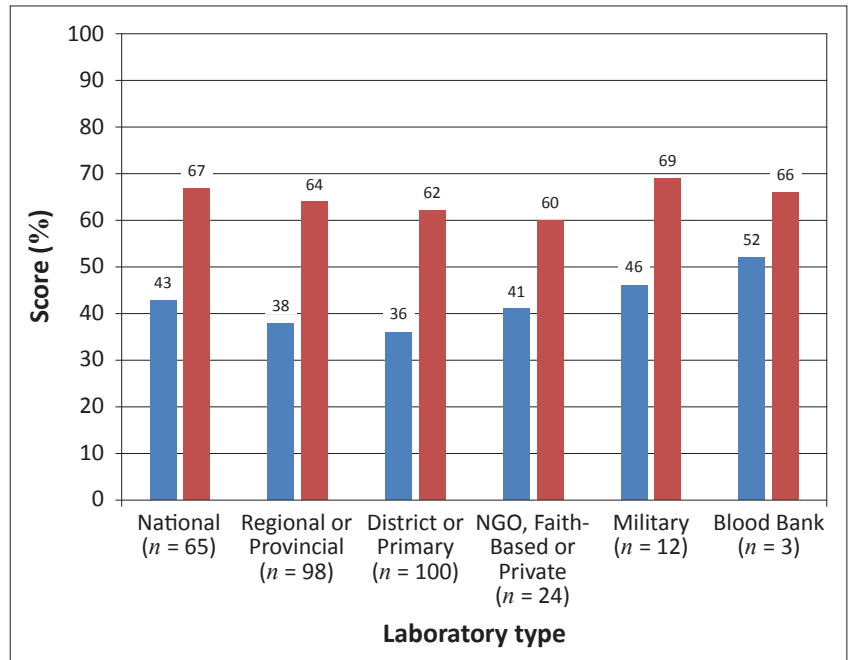

NGO, non-governmental organisation.

FIGURE 3: Baseline and exit scores by laboratory type for the 302 laboratories completing the Strengthening Laboratory Management Toward Accreditation programme 2010-2013 based on the Stepwise Laboratory Quality Improvement Process Towards Accreditation checklist. from baseline to exit (58 percentage points); it took the laboratory only 19 months from initiation of SLMTA to accreditation.

\section{SLMTA implications for laboratory testing}

In total, the 617 SLMTA laboratories conducted an estimated 111 million tests in 2012. Approximately 43.5 million of these tests were conducted by the 302 laboratories that had completed the SLMTA programme by the time of this analysis. Only $16 \%$ of these tests were conducted by laboratories with at least one quality star prior to SLMTA implementation ( $3 \%$ had $\geq 3$ stars); after SLMTA training $68 \%$ of tests were performed by laboratories with at least one quality star ( $28 \%$ had $\geq 3$ stars). This translates to approximately 23 million tests conducted by laboratories that previously had zero stars and now have one or more stars. Furthermore, within the group with zero stars prior to SLMTA implementation, more than one in three tests were performed by laboratories scoring below $35 \%$ on the SLIPTA checklist; after SLMTA completion this proportion

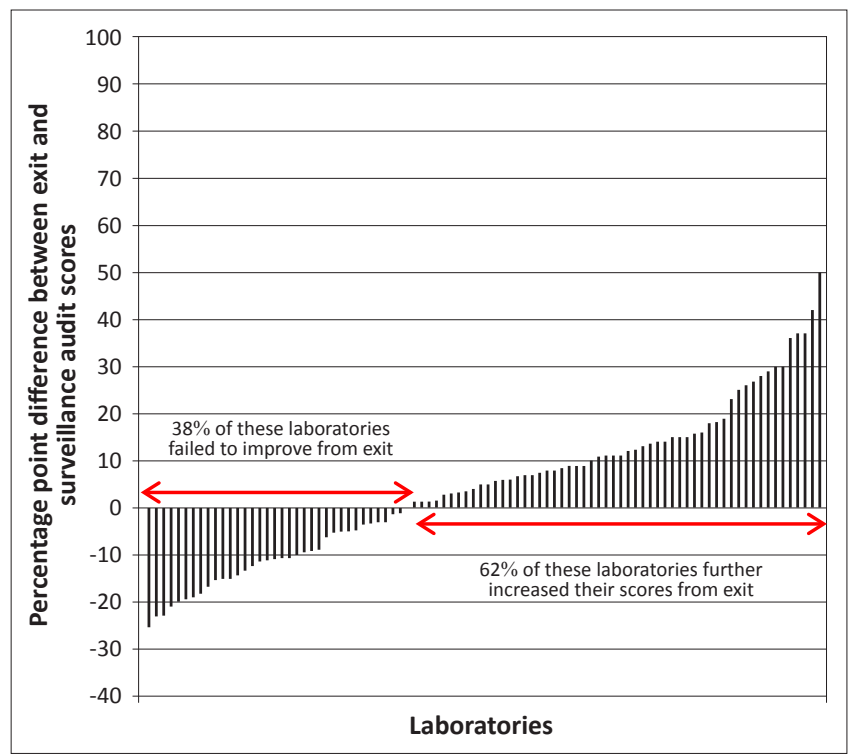

SLMTA, Laboratory Management Toward Strengthening Accreditation.

FIGURE 4: Post-SLMTA surveillance audits ( $n=92$ laboratories), based on the Stepwise Laboratory Quality Improvement Process Towards Accreditation checklist.

TABLE 3: Strengthening Laboratory Management Toward Accreditation laboratories that have achieved formal accreditation as of September 2014.

\begin{tabular}{|c|c|c|c|c|c|c|c|}
\hline Laboratory name & Type of laboratory & Accrediting body & Date accredited & $\begin{array}{l}\text { Date enrolled in } \\
\text { SLMTA* }\end{array}$ & $\begin{array}{l}\text { Time from SLMTA } \\
\text { enrollment to accreditation }\end{array}$ & $\begin{array}{l}\text { Baseline audit } \\
\text { score (\%) }\end{array}$ & $\begin{array}{l}\text { Exit audit } \\
\text { score }(\%)\end{array}$ \\
\hline $\begin{array}{l}\text { Kenya HIV National } \\
\text { Reference laboratory }\end{array}$ & National & $\begin{array}{l}\text { Kenya Accreditation Service } \\
\text { (KENAS) - ISO } 15189\end{array}$ & March 2013 & April 2010 & 35 months & 45 & 95 \\
\hline $\begin{array}{l}\text { The Kenya Medical Research } \\
\text { Institute (KEMRI)/CDC } \\
\text { Tuberculosis Laboratory }\end{array}$ & National & $\begin{array}{l}\text { The South African National } \\
\text { Accreditation System } \\
\text { (SANAS) - ISO } 15189\end{array}$ & July 2013 & February 2012 & 17 months & 75 & 95 \\
\hline $\begin{array}{l}\text { Bahamas HIV National } \\
\text { Reference Laboratory }\end{array}$ & National & $\begin{array}{l}\text { College of American } \\
\text { Pathologists (CAP) }\end{array}$ & September 2013 & May 2011 & 28 months & 38 & 63 \\
\hline $\begin{array}{l}\text { Hai Duong Preventive } \\
\text { Medicine Center, Vietnam }\end{array}$ & Regional/Provincial & $\begin{array}{l}\text { Bureau of Accreditation, } \\
\text { Vietnam - ISO } 17025\end{array}$ & December 2013 & May 2012 & 19 months & 29 & 87 \\
\hline $\begin{array}{l}\text { The Cimas Harare Medical } \\
\text { Laboratory, Zimbabwe }\end{array}$ & Private & $\begin{array}{l}\text { The Southern African } \\
\text { Development Community } \\
\text { Accreditation Services } \\
\text { (SADCAS) - ISO } 15189\end{array}$ & September 2014 & March 2010 & 54 months & 34 & 54 \\
\hline $\begin{array}{l}\text { Bungoma District Hospital } \\
\text { Laboratory, Kenya }\end{array}$ & District & KENAS - ISO 15189 & September 2014 & February 2011 & 43 months & 38 & 92 \\
\hline
\end{tabular}

SLMTA, Strengthening Laboratory Management Toward Accreditation; ISO, International Organization for Standardization; CDC, US Centers for Disease Control and Prevention; *, Date of first SLMTA workshop. 
decreased to one in 50 (Figure 5). Assuming similar quality improvements for the 315 currently-enrolled laboratories, we project the total number of tests conducted by laboratories with one or more stars that had previously been at zero stars to rise to 58 million by the end of 2015 .

\section{Discussion}

Since its launch in 2009, SLMTA has achieved wide global coverage and demonstrated measurable improvement using a standardised checklist, transforming the laboratory landscape in many resource-limited countries worldwide. The results have been remarkable, with audit scores increasing 25 percentage points, and two-thirds of the laboratories that completed the SLMTA programme improving by at least one quality star level. Twenty-three countries have implemented a second cohort of training and 23 million tests conducted by laboratories previously lacking any quality management system are now being conducted by laboratories with at least a basic level of quality in place. The SLMTA programme has the potential to make a substantial and sustainable impact on the quality of laboratory testing and, therefore, patient care.

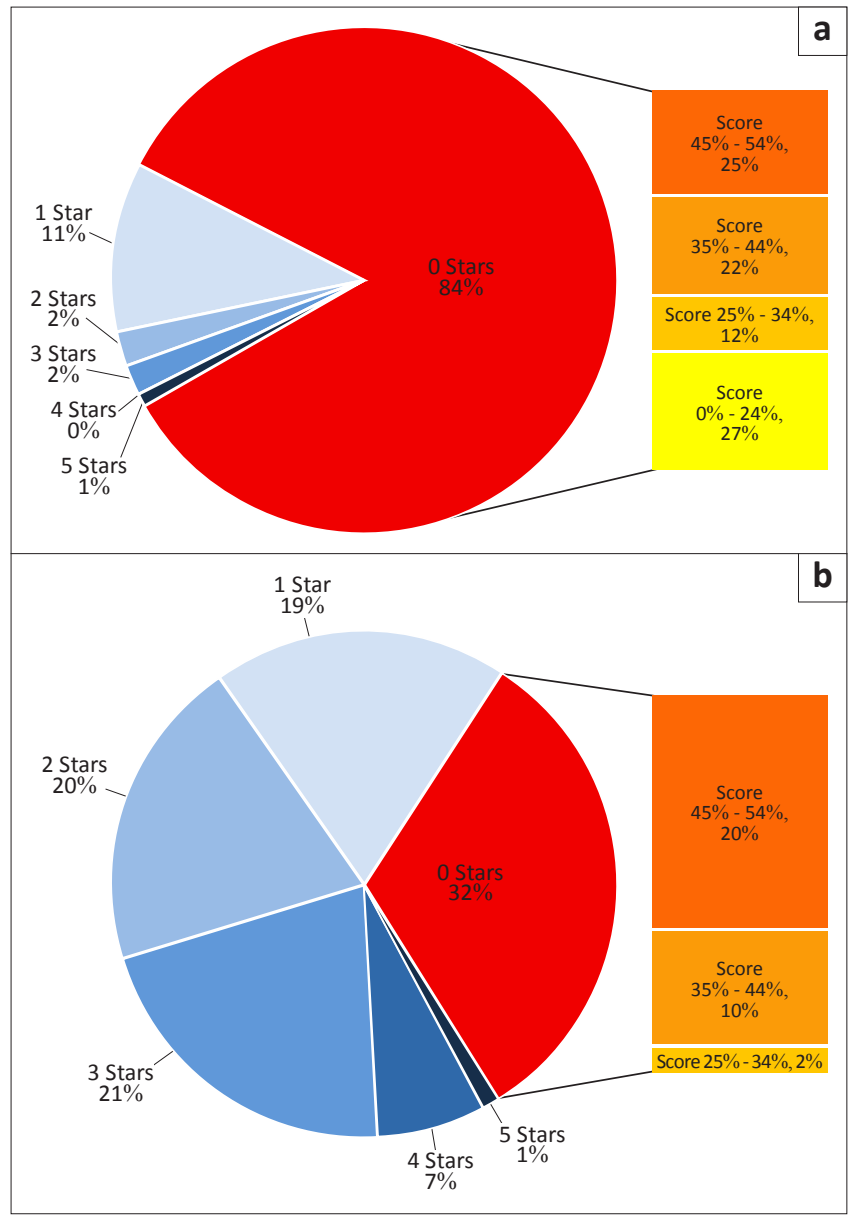

SLMTA, Strengthening Laboratory Management Toward Accreditation.

FIGURE 5: Estimated proportion of $\mathbf{4 3 . 5}$ million tests performed by star leve of laboratories before (a) and after (b) SLMTA implementation, based on the Stepwise Laboratory Quality Improvement Process Towards Accreditation checklist scores for the 302 laboratories that completed the SLMTA programme. Before SLMTA: $16 \%$ of tests were done in laboratories with at least one star. After SLMTA $68 \%$ of tests were done in laboratories with at least one star.
As of August 2014, 102 laboratories from 15 countries in subSaharan Africa had received an official WHO AFRO SLIPTA audit by the African Society for Laboratory Medicine (ASLM) (Maruta T, 2014, personal communication, August 31); ninety-seven (95\%) of these laboratories had gone through the SLMTA programme. It is evident that SLMTA has emerged as a vital strategy in accelerating laboratory preparedness for accreditation in the developing world and in facilitating the fulfillment of ASLM's 2020 Vision, Goal 2: 'by 2020, enroll 2500 laboratories in the WHO SLIPTA quality improvement programme and enable 250 laboratories to achieve accreditation by international standards' ${ }^{\prime}{ }^{9}$

To date, the SLMTA programme has been primarily funded by the US President's Emergency Plan for AIDS Relief (PEPFAR) through CDC and implementation has been limited primarily to PEPFAR-supported countries. Although HIV-focused, these resources have been leveraged to build wide-spread capacity and strengthen the overall laboratory system. ${ }^{10}$ Slowly, partners are joining ranks to help spread the programme. Since 2011, the World Bank has funded five countries (Burundi, Kenya, Rwanda, Tanzania and Uganda) to implement SLMTA in 32 laboratories through its East Africa Public Health Laboratory Network Project. The Southern African Development Community (SADC) will soon partner with the Zimbabwe National Quality Assurance Program in spreading the programme to all 15 member states, some of which are not supported by PEPFAR.

This is the first study to examine the existing level of laboratory quality on a broad international scale. The mean baseline audit score of the 617 SLMTA-enrolled laboratories was $39 \%$, well below the $55 \%$ required to attain even the lowest quality level on the SLIPTA scale, and only $16 \%$ of the laboratories met or surpassed the one-star level. These results paint a bleak picture of the current quality of laboratories in much of the developing world. Whilst the issue of the lack of quality amongst laboratories in developing countries has been acknowledged in numerous publications ${ }^{4,11,12,13,14,15,16,17}$ and a series of policy statements,,$^{18,19,20,21}$ the current study begins to quantify the problem and sheds some light on a potential solution.

The SLMTA curriculum was designed to be closely aligned to ISO 15189; however, it has proven to be suitable to support other standards as well. For example, a SLMTAenrolled laboratory in Vietnam that tests environmental and food samples was accredited to ISO 17025. Two per cent of SLMTA sites are blood banks or blood-transfusion centres, which use different standards and have their own accreditation programmes. In Cameroon, inspired by the transformation achieved by its SLMTA-enrolled laboratory, a hospital adopted SLMTA in order to embark on its own quality improvement journey. ${ }^{22}$ The need for improved quality is so widespread that others have called for the expansion of SLMTA into a programme that helps guide quality improvement in entire hospital and public health systems. ${ }^{23}$ 
According to a May 2013 survey, only two governmentowned medical laboratories in the 48 sub-Saharan African countries outside of South Africa were accredited. ${ }^{11}$ In 2013 to 2014, three more government-owned laboratories in the region (all located in Kenya) were accredited after SLMTA implementation (Table 3). In the same timeframe, two SLMTA laboratories outside of the sub-Saharan region have achieved accreditation, whilst several others are awaiting accreditation assessments. These are only the first of what we anticipate will be many SLMTA laboratories reaching accreditation as the programme matures, since preparing for accreditation is a multi-year process. However, it is not feasible, either economically or programmatically, for all laboratories to pursue accreditation to international standards. As countries develop laboratory strategic plans, they will need to assess the options and develop realistic goals. The Ministry of Health in Uganda, for example, has set a national target of three stars for general hospital laboratories and five stars for national and regional reference laboratories (Lali W, 2014, personal communication, August 31). Regardless of the ultimate goal, the SLMTA programme will provide the tools necessary to guide laboratories in the continuous quality improvement process designed to achieve better patient care.

It is outside the scope of this study to examine how factors such as cohort size, programme length, laboratory type, mentorship model (amount, quality and type) and additional training impact the performance of the programme. However, detailed data are being collected as part of the SLMTA programme, including audit scores for each of the 12 QSEs and laboratory indicators such as turnaround time, specimen rejection rates, equipment downtime, proficiency testing, customer satisfaction and cost. These data are a potential gold mine of information that could be harnessed to identify causative factors of success and to fine-tune the programme with evidence-based strategies for continued improvement. An electronic-tool that will facilitate collection, management, aggregation, analysis and reporting of SLMTA programmatic data on a global level is currently under development by CDC and its partners.

\section{Limitations of the study}

These study results should be interpreted in light of several limitations. Firstly, half of the enrolled laboratories have not yet completed the programme and therefore have no exit audit data. As the programme matures, a higher proportion of the participating laboratories will have full data, reducing the risk of bias. Similarly, whilst we found that most laboratories that conducted surveillance audits continued to improve over a time-span of anywhere from five to 28 months after the SLMTA programme ended, the programme is too young to assess long-term sustainability. Another concern is the quality of the audits, especially in the initial years of the SLMTA programme before formal training and certification of auditors. Whilst the SLIPTA checklist was designed to help standardise audit scoring, some variability may remain; assessment of intra- and interauditor variability is needed.
This was an observational programmatic study. Many factors were not controlled, such as programme duration, size of cohorts, mentorship model and additional training provided to enrolled laboratories. Future studies that compare these factors, as well as results of SLMTA laboratories with non-SLMTA laboratories are needed in order to separate the impact of SLMTA implementation from natural improvement in laboratory quality over the duration of the programme. In addition, estimates of the number of laboratory tests were based on 353 (57\%) laboratories that submitted information; missing data were imputed using average volume by laboratory type, but some uncertainty remains.

Ultimately, a thorough evaluation of the SLMTA programme will require assessment of programme impact on patient care and health outcomes. Systematic evaluation of key indicators is needed, as well as targeted evaluations of programme cost-benefit, the impact of quality improvement on testing error rates and the association of quality services with patient outcomes, so as to determine public and personal health implications.

\section{Conclusion}

Few management and leadership development programmes have been implemented on such a large scale with resultsoriented outcome measures. With data collected from 617 laboratories in 47 countries throughout Africa, the Caribbean, Latin America and Southeast Asia, SLMTA is truly a global effort. It has demonstrated its ability to transform the laboratory landscape in resource-limited countries worldwide. Evidence from this study suggests that the SLMTA programme has the potential to make a substantial and sustainable impact on the quality of laboratory testing and patient care.

\section{Acknowledgements Competing interests}

The authors declare that they have no financial or personal relationship(s) that may have inappropriately influenced them in writing this article.

\section{Authors' contributions}

K.Y. (CDC, Atlanta) managed the global SLMTA programme, collected the data and wrote the manuscript. E.T.L. (CDC, Atlanta) analysed the data and provided substantial input to the manuscript. The collaborating authors provided the data from their respective countries and reviewed the manuscript.

\section{CDC disclaimer}

The findings and conclusions in this report are those of the authors and do not necessarily reflect the official position of the organisations represented by any of the authors, including the CDC, the Department of the Navy, the Department of Defense, or the US Government. 


\section{References}

1. United Nations General Assembly. United Nations Millennium Declaration [document on the Internet]. c2000 [cited 2014 Oct 04]. Available from: http:// www.un.org/millennium/declaration/ares552e.htm

2. Egger $D$, Travis $P$, Dovlo $D$, et al. Strengthening management in low-income countries. Making Health Systems Work: Working Paper No. 1 WHO/HSS/ healthsystems/2005.1 [document on the Internet]. c2005 [cited 2014 Oct 04] Available from: http://www.who.int/management/working_paper_1_en_opt.pdf

3. Yao K, Maruta T, Luman ET, Nkengasong JN. The SLMTA programme: Transforming the laboratory landscape in developing countries. Afr J Lab Med. 2014;3(2), Art. \#194, 8 pages. http://dx.doi.org/10.4102/ajlm.v3i2.194

4. Gershy-Damet GM, Rotz P, Cross D, et al. The World Health Organization African region laboratory accreditation process: Improving the quality of laboratory systems in the African region. Am J Clin Pathol. 2010;134(3):393-400. http:// dx.doi.org/10.1309/AJCPTUUC2V1WJQBM

5. Yao K, McKinney B, Murphy A, et al. Improving quality management systems of laboratories in developing countries: An innovative training approach to accelerate laboratory accreditation. Am J Clin Pathol. 2010;134(3):401-409. http://dx.doi.org/10.1309/AJCPNBBL53FWUIQJ

6. World Health Organization's Regional Office for Africa. WHO guide for the stepwise laboratory improvement process towards accreditation in the African region (with checklist) [document on the Internet]. c2012 [cited 2013 May 31] Available from: http://www.afro.who.int/en/clusters-a-programmes/hss/bloodsafety-laboratories-a-health-technology/blt-highlights/3859-who-guide-for-thestepwise-laboratory-improvement-process-towards-accreditation-in-the-africanregion-with-checklist.html

7. Clinical and Laboratory Standards Institute. Application of a quality managemen system model for laboratory services; Approved Guidelines - Third Edition. CLSI document GP26-A3 [ISBN 1-56238-553-4]. Wayne, PA: Clinical and Laboratory Standards Institute; 2004

8. Gachuki T, Sewe R, Mwangi J, et al. Attaining ISO 15189 accreditation through SLMTA: A journey by Kenya's National HIV Reference Laboratory. Afr J Lab Med. 2014;3(2), Art. \#216, 9 pages. http://dx.doi.org/10.4102/ajlm.v3i2.216

9. The African Society for Laboratory Medicine. ASLM2020: Strategies and vision to strengthen public health laboratory medicine in Africa [document on the Internet]. c2012 [cited 2014 Oct 04]. Available from: http://www.aslm.org/ what-we-do/aslm2020-vision/

10. Committee on the Outcome and Impact Evaluation of Global HIV/AIDS Programs Implemented Under the Lantos-Hyde Act of 2008; Board on Global Health (BGH); Board on Children, Youth, and Families; Institute of Medicine. Evaluation of PEPFAR. Washington, DC: The National Academies Press; 2013.
11. Schroeder LF, Amukele T. Medical laboratories in sub-Saharan Africa that meet international quality standards. Am J Clin Pathol. 2014;141(6):791-795. http:// dx.doi.org/10.1309/AJCPQ5KTKAGSSCFN

12. Alemnji GA, Zeh C, Yao K, et al. Strengthening national health laboratories in sub-Saharan Africa: A decade of remarkable progress. Trop Med Int Health. 2014;19(4):450-458. http://dx.doi.org/10.1111/tmi.12269

13. Petti CA, Polage CR, Quinn TC, et al. Laboratory medicine in Africa: A barrier to effective health care. Clin Infect Dis. 2006;42(3):377-382. http://dx.doi. org/10.1086/499363

14. Guarner J, Duncan A, Nelson A, et al. Laboratory quality control for all. Can this be achieved? Am J Clin Pathol. 2012;138(5):639-641. http://dx.doi.org/10.1309/ AJCP77JZIJAGUIDR

15. Nkengasong JN. A shifting paradigm in strengthening laboratory health systems for global health: acting now, acting collectively, but acting differently. Am J Clin Pathol. 2010;134(3):359-360. http://dx.doi.org/10.1309/AJCPY5ASUEJYQ5RK

16. Nkengasong JN, Nsubuga $P$, Nwanyanwu $O$, et al. Laboratory systems and services are critical in global health: Time to end the neglect? Am J Clin Pathol. 2010;134(3):368-373. http://dx.doi.org/10.1309/AJCPMPSINQ9BRMU6

17. Olmsted $S$, Moore $M$, Meili $R$, et al. Strengthening laboratory systems in resource-limited settings. Am J Clin Pathol. 2010;134(3):374-380. http://dx.doi. org/10.1309/AJCPDQOSB7QR5GLR

18. World Health Organization Regional Office for Africa. The Maputo declaration on strengthening of laboratory systems: [document on the Internet]. c2008 [cited 2014 Jul 21]. Available from: http://www.who.int/diagnostics_laboratory/ Maputo-Declaration_2008.pdf

19. World Health Organization. Joint WHO-CDC conference on health laboratory quality systems, Lyon, France, 9-11 April 2008 [document on the Internet] c2008 [cited 2014 Jul 21]. Available from: http://www.who.int/csr/ihr/lyon/ report20080409.pdf?ua=1

20. World Health Organization Regional Office for Africa. WHO report calls for strengthening public health laboratories [page on the Internet]. c2008 [cited 2014 Jul 21]. Available from: http://www.afro.who.int/en/media-centre/ pressreleases/item/679-who-report-calls

21. African Society for Laboratory Medicine. Ministerial call for action - strengthening laboratory services in Africa. Presented at 2012 International Conference, Cape Town, South Africa [document on the Internet]. c2012 [cited 2014 Jul 21] Available from: http://www.aslm2012.org/docs/ASLM2012\%20Ministerial\%20 Call\%20for\%20Action.pdf

22. Eno LT, Asong T, Ngale E, et al. Driving hospital transformation with SLMTA in a regional hospital in Cameroon. Afr J Lab Med. 2014;3(2), Art. \#221, 5 pages. http://dx.doi.org/10.4102/ajlm.v3i2.221

23. Mataranyika MN, Beukes LK. View from the top: Involvement of Namibia's health ministry in laboratory quality improvement. Afr J Lab Med. 2014;3(2), Art. \#195, 2 pages. http://dx.doi.org/10.4102/ajlm.v3i2.195 


\section{Appendix: Author information}

TABLE: Group Authorship.

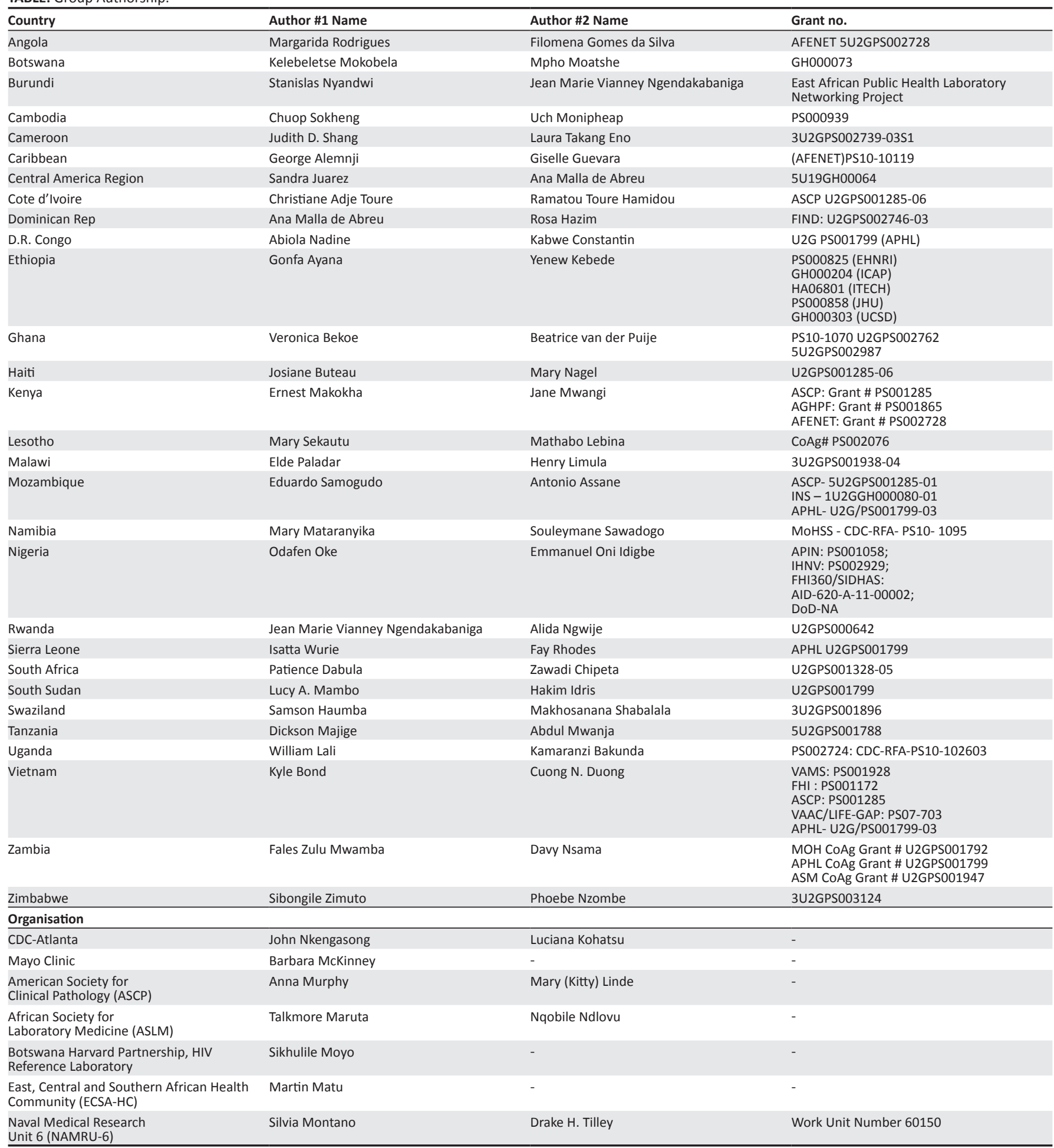

